\title{
Virulence typing and antibiotic susceptibility profiling of thermophilic Campylobacters isolated from poultry, animal, and human species
}

\author{
Neelam Rawat, Maansi, Deepak Kumar and A. K. Upadhyay \\ Department of Veterinary Public Health and Epidemiology, College of Veterinary and Animal Sciences, Govind Ballabh \\ Pant University of Agriculture and Technology, Pantnagar, Uttarakhand, India. \\ Corresponding author: Maansi, e-mail: maansi2000@rediffmail.com \\ Co-authors: NR: neelraw12@gmail.com, DK: kumar310@gmail.com, AKU: ajay.akup@gmail.com \\ Received: 09-06-2018, Accepted: 11-10-2018, Published online: 19-12-2018
}

doi: 10.14202/vetworld.2018.1698-1705 How to cite this article: Rawat N, Maansi, Kumar D, Upadhyay AK (2018) Virulence typing and antibiotic susceptibility profiling of thermophilic Campylobacters isolated from poultry, animal, and human species, Veterinary World, 11(12): 1698-1705.

\begin{abstract}
Background and Aim: Campylobacteriosis finds its place among the four important global foodborne illnesses. The disease, though self-limiting, needs antibacterial therapy in extraintestinal complications. Therefore, the present study was designed to estimate the prevalence of thermophilic Campylobacters in poultry, animals, and humans of the Kumaon region of Uttarakhand.
\end{abstract}

Materials and Methods: A total of 609 samples comprising of poultry ceca $(n=116)$, poultry droppings ( $n=203)$, and feces of pigs $(n=71)$, cattle $(n=61)$, sheep $(n=19)$, goat $(n=17)$, human beings $(n=88)$, and laboratory animals $(n=34)($ rats, rabbits, and guinea pigs) were collected. The thermophilic Campylobacters, Campylobacter jejuni and Campylobacter coli were confirmed using multiplex polymerase chain reaction. The isolates were also screened for the presence of virulence genes, and their antibiotic susceptibility testing was done against eight antibiotics.

Results: An overall prevalence of $6.24 \%$ was revealed with highest from poultry ceca $(15.52 \%)$, followed by poultry droppings (5.91\%), cattle feces (4.92\%), human stools $(3.40 \%)$, and pig feces $(2.82 \%)$. The virulence genes, namely $c a d F$, flaA, virB 11, and pldA, were present in $38(100 \%), 37(97.37 \%), 7(18.42 \%)$, and $14(36.84 \%)$ isolates, respectively. All the isolates were resistant to nalidixic acid, while all were sensitive to erythromycin and co-trimoxazole.

Conclusion: It was concluded that the animals and humans in the region harbored the thermophilic Campylobacters which may contribute to the human illness. Resistance shown among the isolates may complicate the antimicrobial therapy.

Keywords: antibiotic susceptibility, thermophilic Campylobacters, virulence.

\section{Introduction}

Infections occurring due to the consumption of contaminated food are of a growing public health concern. These contaminated or unsafe foods pose a global threat affecting persons of all age groups. Food may get contaminated during any point of production and/or distribution by a number of microbes. Of all the food pathogens, Campylobacters have become a leading cause of enteric infections in both developing and developed countries. The Campylobacters have a broad animal reservoir. They are inhabitants of the intestinal tract of various domestic and wild animals, especially birds which are generally asymptomatic carriers. Therefore, inadequately cooked meat, particularly poultry, contaminated drinking water, unpasteurized milk, ready to eat food products, fecal runoff of birds and domestic animals contaminating surface water, and direct contact with animals act as the main source of the organism. Contaminated

Copyright: Rawat, et al. Open Access. This article is distributed under the terms of the Creative Commons Attribution 4.0 International License (http://creativecommons.org/licenses/by/4.0/), which permits unrestricted use, distribution, and reproduction in any medium, provided you give appropriate credit to the original author(s) and the source, provide a link to the Creative Commons license, and indicate if changes were made. The Creative Commons Public Domain Dedication waiver (http://creativecommons.org/ publicdomain/zero/1.0/) applies to the data made available in this article, unless otherwise stated. food is the primary mode of infection with poultry being the most common food source for humans [1]. Prevalence of Campylobacters in poultry has been reported by many authors [2-4]. In humans, the disease, campylobacteriosis is characterized by bloody diarrhea, fever, severe abdominal pain, and headache. Fever generally persists for up to 1 week in more than $90 \%$ of the patients; however, $50 \%$ of persons infected with Campylobacters remain asymptomatic [5]. It is a gastrointestinal disorder that generally affects infants, elderly people, and immunocompromised individuals. Most people suffering from campylobacteriosis recover within 2-5 days, but it may take up to 10 days in some cases. A very small dose of 500 cells may be infectious and sufficient to produce gastroenteritis. Common long-term complications of campylobacteriosis are Guillain-Barre syndrome, inflammatory bowel disease, bacteremia, rheumatoid arthritis, along with local complications such as cholecystitis, pancreatitis, peritonitis, massive gastrointestinal hemorrhage, thyroiditis, and prosthetic joint infection. Over 2.4 million persons annually or $0.8 \%$ of the total population [6] are affected making it a very important organism from a socioeconomic perspective. However, many of the cases go undiagnosed. The disease has a long back existence, and its recognition as a common infection is owed to improved laboratory 
methods. It still remains a high research priority to improve the strategies for management as well as prevention of the disease.

Molecular methods are useful in the identification of thermophilic Campylobacters as they enhance the sensitivity and specificity of the detection process. Polymerase chain reaction (PCR)-based species identification methods for Campylobacter spp. provide more reliable identification. Gorkiewicz et al. [7] recommended 16SrRNA sequence analysis as an effective, reliable, and rapid procedure for the specific identification of Campylobacters. Molecular techniques have come a long way in the characterization of microbes. Despite higher recovery rates of Campylobacters as foodborne pathogens, the specific virulence and pathogenic mechanisms of Campylobacter spp. infection is still poorly understood. The putative virulence factor for adhesion $(c a d \mathrm{~F}, d n a \mathrm{~J}, j l p \mathrm{~A}, p l d \mathrm{~A}, r a c \mathrm{R}$, and $v i r \mathrm{~B} 11)$ and invasion of epithelial cells (iam $\mathrm{A}, \operatorname{cia} \mathrm{B}$, and $c e u \mathrm{E})$, toxin production $(c d t \mathrm{~A}, c d t \mathrm{~B}, c d t \mathrm{C}$, and $w l a \mathrm{~N}$ ), and flagellar motility (fla $\mathrm{A}, f l a \mathrm{~B}, f l h \mathrm{~A}, f l h \mathrm{~B}$, $f l g \mathrm{~B}, f l g \mathrm{E} 2, f l i \mathrm{M}$, and $f l i \mathrm{Y}$ ) are thought to be important virulence mechanisms. Different studies in this regard have indicated the role of different virulence markers for adherence, invasion, and colonization of the organism in humans and animals. These virulence-related factors contribute to survival and establishment of the disease in host, thus modulating the clinical presentation of the disease. Antimicrobial agents are used for the early recovery of extraintestinal infections in immunocompromised patients or whenever clinical therapy is needed. The emergence of antimicrobial-resistant (AMR) Campylobacters has alerted toward the chances of increased invasive illness. The resistance has been linked to the illicit use of antimicrobials in animal feeds, food animals, and flock treatment of animals. Few antibiotics such as macrolides (erythromycin [ERY]) and fluoroquinolones (ciprofloxacin [CIP]) used as drug of choice have shown resistance against Campylobacter spp. [8]. Newer antibiotics are being continuously added to the list every year.

The present study was, therefore, undertaken to characterize the isolated Campylobacters on the presence of virulence genes and the phenotypic antibiotic resistance.

\section{Materials and Methods}

Ethical approval

Samples were collected as per standard sample collection procedure.

\section{Sample collection and processing}

A total of 609 samples comprising of poultry ceca $(n=116)$, poultry droppings $(n=203)$, and feces of pigs $(n=71)$, cattle $(n=61)$, sheep $(n=19)$, goat $(n=17)$, human beings $(n=88)$, and laboratory animals $(n=34)$ (rats, rabbits, and guinea pigs) were collected from Uttarakhand state of India. Sterile $100 \mathrm{ml}$ Whirl-Pak bags (Nasco, Fort Atkinson, WI) were used to collect the samples. The samples were collected aseptically and immediately brought to the laboratory for processing as per previously published protocols $[9,10]$.

In brief, the poultry ceca and poultry fecal samples were streaked directly onto the modified charcoal-cefoperazone-deoxycholate agar (mCCDA, HiMedia, India) plates and incubated at $42^{\circ} \mathrm{C}$ with $5 \% \mathrm{CO}_{2}$ in a $\mathrm{CO}_{2}$ incubator for $48 \mathrm{~h} \mathrm{[10].} \mathrm{However,}$ human and other animal fecal samples (1 g) were initially enriched in $9 \mathrm{ml}$ Bolton Broth (Oxoid, UK) supplemented with 5\% sheep blood. Thereafter, a loopful of the enriched broth suspension was streaked onto mCCDA plates and was incubated at the same time-temperature combination. The characteristic Campylobacter colonies (1-2 mm size, circular, flat to slightly raised, sticky, spreading, and shiny gray) were selected from each plate and tested biochemically.

\section{Biochemical and molecular confirmation}

All the presumptive Campylobacter isolates showing catalase and oxidase positive reaction while urease and TSI negative reaction were subjected to DNA isolation using Hi-PurA genomic DNA extraction kit (Hi-media).

A simplex PCR assay targeting the 16SrRNA [11] was used for the Campylobacter genus identification. The primer sequence and the cyclic conditions were used as per Linton et al. [11] for Campylobacter genus. All PCR confirmed Campylobacter isolates were stored as $20 \%$ glycerol stock at $-80^{\circ} \mathrm{C}$.

\section{Multiplex PCR}

Multiplex PCR was carried out for the identification of genus as well as species of the isolates. Multiplex PCR included amplification of $c a d F$ gene for genus identification [12], whereas hipO gene [11] and asp gene [11] amplification for the identification of Campylobacter jejuni and Campylobacter coli, respectively. The primer sequence and the cyclic conditions were used as per Linton et al. [11] and Nayak et al. [12] for Campylobacter genus and species, respectively.

\section{Detection of virulence genes}

All Campylobacter isolates were screened for the presence of various virulence genes by PCR. Virulence genes screened were flaA [13], virB11 [14], and pldA [15]. PCR reaction and cycling conditions were used as described earlier in respective references.

\section{Antimicrobial susceptibility testing}

The AMR profile of Campylobacter isolates was determined using standard Kirby-Bauer disc diffusion method as described by Taremi et al. [16]. A total of 38 revived isolates were tested against a panel of eight antibiotics that included ampicillin (AMP, $10 \mu \mathrm{g}$ ), gentamicin (GEN, $10 \mu \mathrm{g})$, ERY $(15 \mu \mathrm{g})$, levofloxacin (LE, $5 \mu \mathrm{g})$, CIP $(5 \mu \mathrm{g})$, nalidixic acid (NA, $30 \mu \mathrm{g}$ ), ceftriaxone (CTR, $30 \mu \mathrm{g}$ ), and co-trimoxazole (COT, $25 \mu \mathrm{g}$ ) (HiMedia). The isolates were revived on mCCDA plates supplemented with FD009 supplement. The growth suspension prepared in Tryptic soy broth and compared with $0.5 \mathrm{McF}$ arland standard was spread on Mueller-Hinton agar plates supplemented with $7 \%$ 
sheep blood and incubated at $42^{\circ} \mathrm{C}$ in a $\mathrm{CO}_{2}$ incubator at $5 \% \mathrm{CO}_{2}$ tension for $24 \mathrm{~h}$. Zone diameter was measured and breakpoints were interpreted based on the recommendations of the Clinical and Laboratory Standards Institute standards for disc diffusion assay (CLSI 2016).

\section{Results}

\section{Isolation and molecular confirmation}

Of 609 samples (poultry ceca [ $\mathrm{n}=116]$, poultry droppings $[n=203]$, and feces of pigs $[n=71]$, cattle $[\mathrm{n}=61]$, sheep $[\mathrm{n}=19]$, goat $[\mathrm{n}=17]$, human beings $[\mathrm{n}=88]$, and laboratory animals $[\mathrm{n}=34])$ screened, 38 were confirmed as positive for Campylobacter yielding a prevalence of $6.24 \%$.

All the isolates produced a genus-specific amplicon of $816 \mathrm{bp}$ in 16SrRNA Campylobacter genus-specific PCR (Figure-1).

\section{Multiplex PCR for species identification}

On performing the multiplex PCR, all the 38 isolates amplified cadF gene and produced $400 \mathrm{bp}$ amplicon suggesting the isolates belonging to genus Campylobacter. C. coli and C. jejuni species targeting asp gene (500 bp) and hipO gene (735 bp), respectively, were amplified in $29(\mathrm{n}=38)$ and $9(\mathrm{n}=38)$ isolates revealing a prevalence of $76.32 \%$ and $23.68 \%$, respectively (Figure-2).

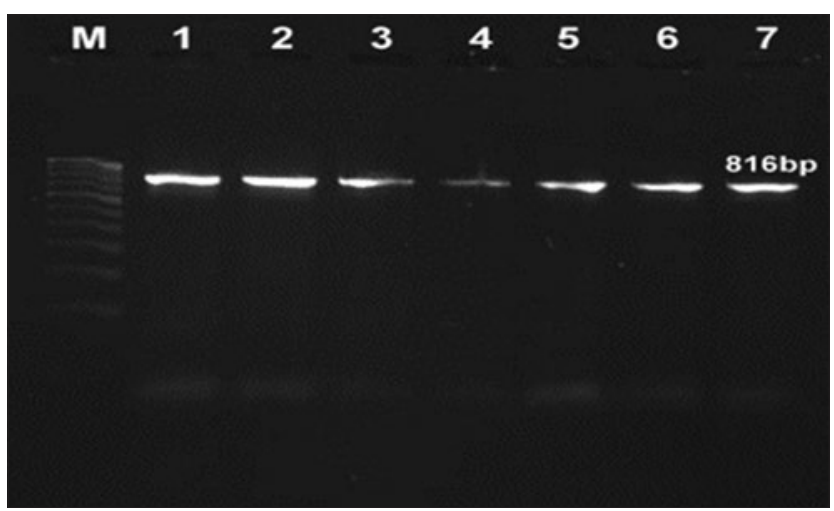

Figure-1: Agarose gel showing polymerase chain reaction product specific for genus Campylobacter spp. (16SrRNA), Lane M: 100bp ladder, Lanes 1-7: Campylobacter isolates (816 bp).

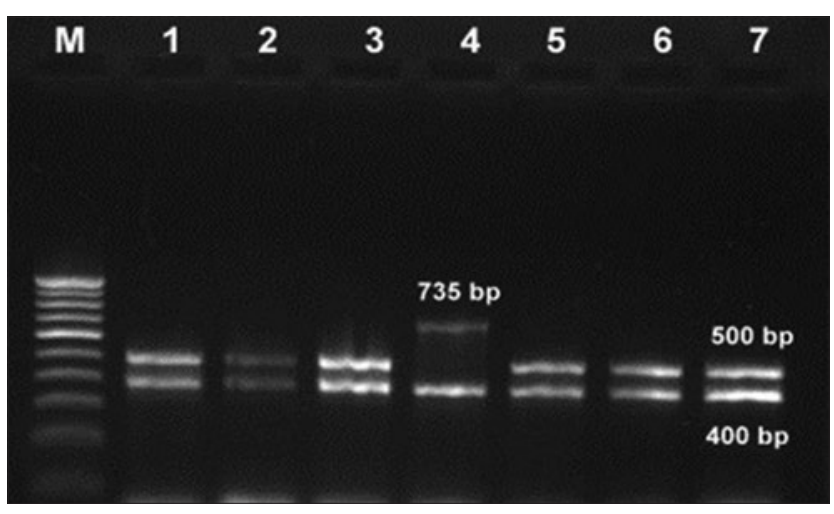

Figure-2: Multiplex polymerase chain reaction for Campylobacter genus and species identification. Lane M: 100 bp ladder, Lanes 1, 2, 3, 5, 6, 7: Campylobacter coli, Lane 4: Campylobacter jejuni.
Prevalence of Campylobacters among various sources

Of 609 samples screened, 38 were found positive for Campylobacter spp. with a prevalence of $6.24 \%$. Of a total of 38 thermophilic Campylobacters detected, $9(23.68 \%)$ were identified as C. jejuni and $29(76.32 \%)$ as $C$. coli. Highest isolation was recorded from poultry ceca $(15.52 \%)$, followed by poultry droppings $(5.91 \%)$, cattle feces $(4.92 \%)$, human stools (3.40\%), and pig feces (2.82\%). All sheep, goat, and laboratory animal fecal samples tested were negative for Campylobacter spp. (Table-1).

\section{Virulence typing}

Virulence typing was performed using four genes as targets. The results suggested that $c a d \mathrm{~F}$, vir B11, and pldA genes were present in 38 (100\%), 7 (18.42\%), and 14 (36.84\%) isolates, respectively (Figures-3-5). The second highest prevalence was found of flaA (flagellar motility) gene that was amplified in 37(97.37\%) isolates. A total of 7 isolates (18.42\%), 5 of $C$. jejuni and 2 of $C$. coli, were found to express all the four virulent genes (cad $\mathrm{F}$, fla $\mathrm{A}$, vir $\mathrm{B} 11$, and pld $\mathrm{A})$ as shown in Tables-2 and 3.

\section{AMR}

Antibiotic resistance profile Campylobacter isolates were determined using eight antibiotics according to the CLSI 2015. Comparison of antibiotic susceptibilities of the isolates from different sources is shown in Tables-4 and 5. All isolates $(100 \%, n=38)$ were resistant to NA, while all

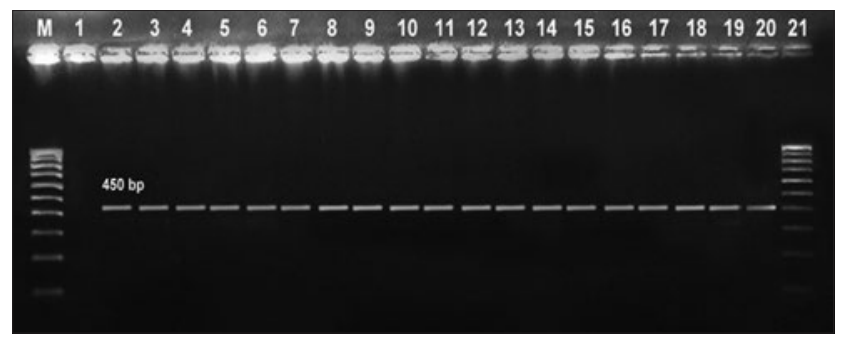

Figure-3: Gel electrophoresis of polymerase chain reaction (PCR) product flaA (450 bp), Lane M: 100 bp ladder, Lane 1: Escherichia coli, Lanes 2-20: flaA PCR product.

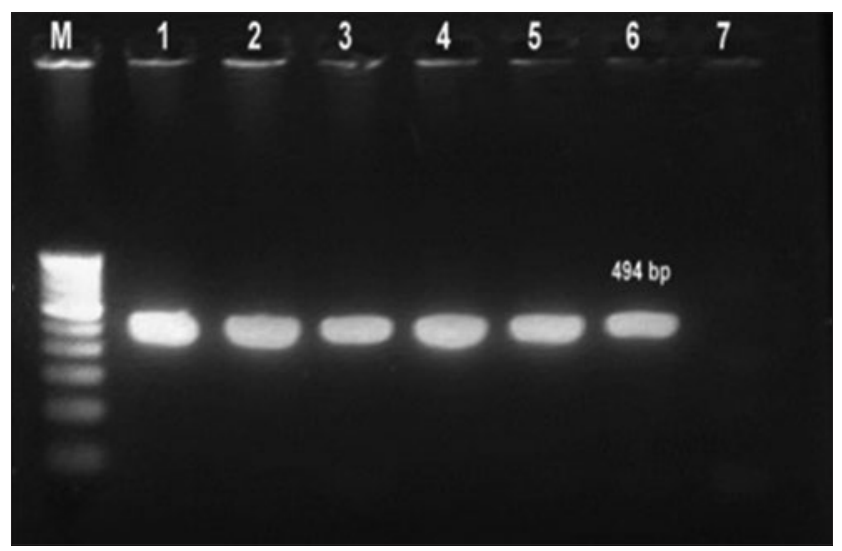

Figure-4: Gel electrophoresis of polymerase chain reaction (PCR) product virB11 (494 bp), Lane M: 100 bp ladder, Lane 7: Escherichia coli, Lanes 1-6: virB11 PCR product. 
were sensitive to ERY and COT. Only $2(5.3 \%)$ C. coli isolates were resistant to AMP and 1 (2.6\%) C. jejuni was resistant to GEN. Of all the isolates, $13.16 \%, 18.42 \%, 23.68 \%, 36.84 \%$, and $23.68 \%$ were intermediately resistant to AMP, GEN, LE, $\mathrm{CIP}$, and CTR, respectively, probably reflecting a shift toward resistance.

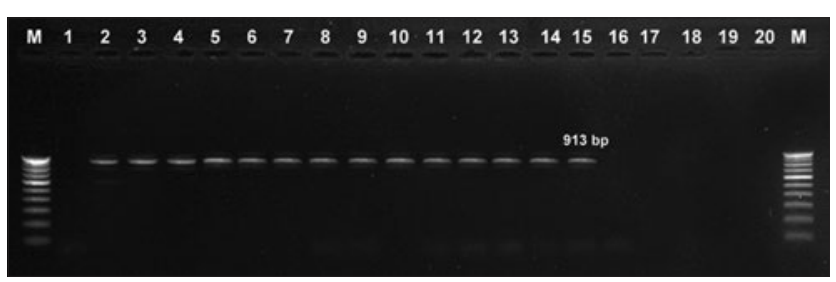

Figure-5: Gel electrophoresis of polymerase chain reaction (PCR) product pldA (913 bp), Lane M: 100 bp ladder, Lane 1 - Escherichia coli, Lanes 2-15: pldA PCR product.

\section{Discussion}

Campylobacter is one of the leading causes of gastrointestinal illnesses worldwide. The present study was done to determine the prevalence of thermophilic Campylobacters (C. jejuni and C. coli), their presence of virulence genes, and the antimicrobial susceptibility of the obtained isolates. Of 609 samples screened, 38 were detected to be positive for Campylobacter spp. showing the overall prevalence rate to be $6.24 \%$. The findings were in accordance with the work of Rajagunalan [17] and Pandey [18] who accounted $6.9 \%$ and $5.34 \%$ prevalence rate of Campylobacter spp. in the same area, respectively. However, there are reports of a bit higher prevalence in the same study region $16 \%$ [19], $11.66 \%$ [20], and $13.54 \%$ [21], and the reason probably could be the

Table-1: Distribution of Campylobacter isolates across various samples.

\begin{tabular}{lcccc}
\hline Sample source & $\begin{array}{c}\text { Number of samples } \\
\text { collected }\end{array}$ & $\begin{array}{c}\text { Number of positive } \\
\text { samples (\%) }\end{array}$ & $\begin{array}{c}\text { Campylobacter } \\
\text { jejuni (\%) }\end{array}$ & $\begin{array}{c}\text { Campylobacter } \\
\text { coli (\%) }\end{array}$ \\
\hline Poultry droppings & 203 & $12(5.91)$ & $3(25)$ & $9(75)$ \\
Poultry ceca & 116 & $18(15.52)$ & $2(11.11)$ & $16(88.89)$ \\
Cattle feces & 61 & $3(4.92)$ & $1(33.33)$ & $2(66.67)$ \\
Sheep and goat feces & 36 & $0(0)$ & $0(0)$ & $0(0)$ \\
Pig feces & 71 & $2(2.82)$ & $0(0)$ & $2(100)$ \\
Laboratory animals' feces & 34 & $0(0)$ & $0(0)$ & $0(0)$ \\
Human stools & 88 & $3(3.41)$ & $9(100)$ & $0(0)$ \\
Total & 609 & $38(6.24)$ & & $29(76.32)$ \\
\hline
\end{tabular}

Table-2: Prevalence of virulent genes in Campylobacter isolates recovered from various sources.

\begin{tabular}{|c|c|c|c|c|c|}
\hline \multirow[t]{2}{*}{ Source } & \multirow[t]{2}{*}{ Number of isolates } & \multicolumn{4}{|c|}{ Virulence genes detected in Campylobacter spp. } \\
\hline & & $\operatorname{cadF}(\%)$ & flaA (\%) & virB11 (\%) & pldA (\%) \\
\hline Poultry droppings & 12 & $12(100)$ & $12(100)$ & $2(16.67)$ & $5(41.67)$ \\
\hline Poultry ceca & 18 & $18(100)$ & $18(100)$ & $3(16.67)$ & $4(22.22)$ \\
\hline Cattle feces & 3 & $3(100)$ & $2(66.67)$ & $1(33.33)$ & $2(66.67)$ \\
\hline Sheep and goat feces & 0 & $0(0)$ & $0(0)$ & $0(0)$ & $0(0)$ \\
\hline Pig feces & 2 & $2(100)$ & $2(100)$ & $0(0)$ & $0(0)$ \\
\hline Laboratory animals' feces & 0 & $0(0)$ & $0(0)$ & $0(0)$ & $0(0)$ \\
\hline Human stools & 3 & $3(100)$ & $3(100)$ & $1(33.33)$ & $3(100)$ \\
\hline Total & 38 & $38(100)$ & $37(97.37)$ & $7(18.42)$ & $14(36.84)$ \\
\hline
\end{tabular}

Table-3: Distribution of virulent genes among the Campylobacter isolates.

\begin{tabular}{|c|c|c|c|c|c|c|}
\hline \multirow[t]{2}{*}{ Source } & \multirow[t]{2}{*}{ Campylobacter spp. } & \multirow{2}{*}{$\begin{array}{l}\text { Total number of } \\
\text { isolates }\end{array}$} & \multicolumn{4}{|c|}{ Virulent genes detected in Campylobacter spp. } \\
\hline & & & $\operatorname{cad} \mathbf{F}$ & flaA & virB11 & pldA \\
\hline \multirow[t]{2}{*}{ Poultry droppings } & C. jejuni & 3 & 3 & 3 & 2 & 2 \\
\hline & C. coli & 9 & 9 & 9 & 0 & 3 \\
\hline \multirow[t]{2}{*}{ Poultry ceca } & C. jejuni & 2 & 2 & 2 & 1 & 1 \\
\hline & C. coli & 16 & 16 & 16 & 2 & 3 \\
\hline \multirow[t]{2}{*}{ Cattle feces } & C. jejuni & 1 & 1 & 1 & 1 & 1 \\
\hline & C. coli & 2 & 2 & 1 & 0 & 1 \\
\hline \multirow{2}{*}{$\begin{array}{l}\text { Sheep and goat } \\
\text { feces }\end{array}$} & C. jejuni & 0 & 0 & 0 & 0 & 0 \\
\hline & C. coli & 0 & 0 & 0 & 0 & 0 \\
\hline \multirow[t]{2}{*}{ Pig feces } & C. jejuni & 0 & 0 & 0 & 0 & 0 \\
\hline & C. coli & 2 & 2 & 2 & 0 & 0 \\
\hline \multirow{2}{*}{$\begin{array}{l}\text { Laboratory animals' } \\
\text { feces }\end{array}$} & C. jejuni & 0 & 0 & 0 & 0 & 0 \\
\hline & C. coli & 0 & 0 & 0 & 0 & 0 \\
\hline \multirow[t]{2}{*}{ Human stools } & C. jejuni & 3 & 3 & 3 & 1 & 3 \\
\hline & C. coli & 0 & 0 & 0 & 0 & 0 \\
\hline
\end{tabular}

C. jejuni=Campylobacter jejuni, C. coli=Campylobacter coli 
Available at www.veterinaryworld.org/Vol.11/December-2018/9.pdf

Table-4: Antibiotic sensitivity pattern of the obtained thermophilic Campylobacter isolates.

\begin{tabular}{lccccc}
\hline Antibiotic & $\begin{array}{c}\text { Total } \\
\text { isolates }\end{array}$ & $\begin{array}{c}\text { Number } \\
\text { resistant }\end{array}$ & $\begin{array}{c}\text { Number } \\
\text { intermediate }\end{array}$ & $\begin{array}{c}\text { Number } \\
\text { sensitive }\end{array}$ & $\begin{array}{c}\text { \% of resistant } \\
\text { isolates }\end{array}$ \\
\hline AMP & 38 & 2 & 5 & 31 & 5.3 \\
GEN & 38 & 1 & 7 & 30 & 2.6 \\
ERY & 38 & 0 & 0 & 38 & 0.0 \\
LE & 38 & 0 & 14 & 29 & 0.0 \\
CIP & 38 & 0 & 0 & 0 & 0.0 \\
NA & 38 & 38 & 9 & 29 & 100.0 \\
CTR & 38 & 0 & 0 & 38 & 0.0 \\
COT & 38 & 0 & 9 & 0.0 \\
\hline
\end{tabular}

$\mathrm{AMP}=$ Ampicillin, GEN=Gentamicin, ERY=Erythromycin, LE=Levofloxacin, CIP=Ciprofloxacin, NA=Nalidixic acid, CTR $=$ Ceftriaxone, COT=Co-trimoxazole

Table-5: Antibiotic sensitivity pattern among Campylobacter isolates.

\begin{tabular}{|c|c|c|c|c|}
\hline \multirow[t]{2}{*}{ Antibiotics } & \multirow[t]{2}{*}{ Campylobacter spp. } & \multicolumn{3}{|c|}{ Number of isolates } \\
\hline & & Resistant & Intermediate & Sensitive \\
\hline \multirow[t]{2}{*}{ Ampicillin } & C. jejuni & 0 & 1 & 8 \\
\hline & C. coli & 2 & 4 & 23 \\
\hline \multirow[t]{2}{*}{ Gentamicin } & C. jejuni & 1 & 1 & 7 \\
\hline & C. coli & 0 & 6 & 23 \\
\hline \multirow[t]{2}{*}{ Erythromycin } & C. jejuni & 0 & 0 & 9 \\
\hline & C. coli & 0 & 0 & 29 \\
\hline \multirow[t]{2}{*}{ Levofloxacin } & C. jejuni & 0 & 1 & 8 \\
\hline & C. coli & 0 & 8 & 21 \\
\hline \multirow[t]{2}{*}{ Ciprofloxacin } & C. jejuni & 0 & 3 & 6 \\
\hline & C. coli & 0 & 11 & 18 \\
\hline \multirow[t]{2}{*}{ Nalidixic acid } & C. jejuni & 9 & 0 & 0 \\
\hline & C. coli & 29 & 0 & 0 \\
\hline \multirow[t]{2}{*}{ Ceftriaxone } & C. jejuni & 0 & 2 & 7 \\
\hline & C. coli & 0 & 7 & 22 \\
\hline \multirow[t]{2}{*}{ Co-trimoxazole } & C. jejuni & 0 & 0 & 9 \\
\hline & C. coli & 0 & 0 & 29 \\
\hline
\end{tabular}

C. jejuni=Campylobacter jejuni, C. coli=Campylobacter coli

variation in species of host, time and season of sample collection, and the difference in the sample source of various species. This study also showed that $C$. coli $(29 / 38,76.32 \%)$ was more prevalent than C. jejuni $(9 / 38,23.68 \%)$ isolates which was incorcondance with Rajagunalan [17] and Kumar [20]. In contrast to these findings, many workers including Rajendran et al. [22] and Deckert et al. [23] have reported the higher presence of $C$. jejuni than $C$. coli. The variation in the prevalence of $C$. jejuni and C. coli could be due to difference in the samples, animal species screened, and the geographical location of the study. The use of growth promoters and increased AMR in C. coli has also been reasoned for the variation [24].

Among different sample sources, the highest isolation rate was observed from poultry ceca $(15.52 \%)$, followed by poultry droppings $(5.91 \%)$, cattle feces $(4.92 \%)$, human stools $(3.40 \%)$, and pig feces $(2.82 \%)$. The observations were in agreement with the findings of Humphrey et al. [25], who observed that, other than poultry digestive tract, digestive tracts of cattle, pigs, and human beings also act as the significant reservoir for Campylobacter species. The isolation rate in poultry ceca was higher $(15.52 \%)$ than poultry droppings (5.91\%). The difference could be because organisms undergo stress after excretion which may affect its survival and recovery rate. Moreover, keeping period of a bird in a flock enhances the colonization of Campylobacters. The collection of fecal and cecal samples from the same bird might give a clear picture of the prevalence of the organism.

None of the isolates were recovered from sheep and goat feces. Low prevalence of Campylobacters in sheep and goat has been reported by Salihu et al. [26], Zweifel et al. [27], and Cortes et al. [28] who reported a very low prevalence of Campylobacter spp. in sheep and goats as compared to other animals. As a contradiction to this finding, Lazou et al. [29], Mpalang et al. [30], and Karikari et al. [31] have recorded high prevalence in sheep and goat. The fecal samples of laboratory animals also did not yield any isolate which was dissimilar to the findings of Jensen et al. [32] and Nkogwe et al. [33] who reported C. jejuni infection in rats. Our findings in case of sheep, goat, and laboratory animals differed probably due to a lower number of samples screened. Moreover, better husbandry practices [26] followed could have resulted in the absence of Campylobacters. The laboratory animals were kept in a strict hygienic environment separated from other animals in the medical as well as veterinary colleges which could be the reason for the absence of Campylobacter organism from these samples. 
Virulence typing was performed using four genes as targets. Of all the 38 isolates, all the isolates $(100 \%)$ showed the presence of $c a d F$ genes. The other three flaA, vir $\mathrm{B} 11$, and $p l d \mathrm{~A}$ genes were present in 37 (97.37\%), 7 (18.42\%), and 14 (36.84\%) isolates, respectively.

The $c a d \mathrm{~F}$ and fla $\mathrm{A}$ genes responsible for the expression of adherence and colonization were highly detectable in all the isolates. The presence of $c a d \mathrm{~F}$ gene highly conserved in Campylobacters and regarded as genus-specific has been reported by Konkel et al. [34] and Wieczorek et al. [35]. This protein is important for full binding capacity of the Campylobacters to the host intestinal epithelial cells. Rozynek et al. [36] and Wieczorek and Osek [37] have also identified this virulence gene to be present in the feces of poultry, animal, and human isolates. The presence of flaA gene which determines flagellar motility responsible for motility and colonization of enterocytes is one of the best-studied virulence markers and in this study was present in 37 (97.37\%) isolates. Previous studies have also indicated that the detection rate of fla $\mathrm{A}$ gene is high $(>95 \%)$.

The virB11 and the pldA (phospholipase A) genes are responsible for invasion and survival within the host cells. The virB11 gene was rarest among all the studied genes and was present in the isolates obtained from poultry droppings $(16.67 \%)$, poultry ceca $(16.67 \%)$, cattle feces $(33.33 \%)$, and human stools (33.33\%). Bang et al. [38] also found only $7.5 \%$ of the isolates from pigs and cattle to be positive for virB11. Studies conducted on poultry, animals, and humans by Biswas et al. [15], Talukder et al. [39], Koolman et al. [40], and Jribi et al. [41] also, in fact, did not find the presence of virB11 gene. The pldA gene was also detected in $36.84 \%$ isolates. Melo et al. [42] also detected the presence of pldA gene in $63.65 \%$ of the $C$. jejuni strains isolated from chicken meat. The presence of these genes poses a potential hazard to human health.

Antibiotic susceptibility profile of all the 38 isolates $(29$ C. coli and 9 C. jejuni) revealed $100 \%$ resistance to NA. Only $2(5.3 \%) C$. coli and $1(2.6 \%)$ C. jejuni were resistant to AMP and GEN, respectively. Of all the isolates, $13.16 \%, 18.42 \%, 23.68 \%$, $36.84 \%$, and $23.68 \%$ were intermediately sensitive to AMP, GEN, LE, CIP, and CTR, respectively, probably reflecting a shift toward resistance. The variation in the antimicrobial sensitivity pattern of the Campylobacter isolates was noticed among various reports. A significant increase in the resistance for NA (46.7\% of the isolates) and CIP (52.2\%) was also observed in Spain [43]. However, in our study, all the isolates were found to be resistant to NA but sensitive to CIP and LE. Furthermore, $100 \%$ resistance to cephalothin and COT and 100\% sensitivity to AMP, GEN, and ERY were reported [17]. Only $71.4 \%$ of isolates had sensitivity against NA. $80 \%$ and $77 \%$ of Campylobacter isolates obtained from Thailand and
India, respectively, were found to be resistant against fluoroquinolones [44]. Higher resistance rates to CIP (95.8-99\%, 85.4\%, and 91\%) have been reported in China [45], the United Arab Emirates [46], and South Africa [47], respectively. The development of resistance in the poultry and animals of the study area is a potential threat to human health. There is much fear that this resistance may spread to environment [48] which may further lead to difficult to treat cases.

\section{Conclusion}

The present study highlights the existence of thermophilic Campylobacters in poultry, animals, and even in human samples. The recovery of positive isolates from humans emphasizes human-animal proximity that must have led to the transmission. The presence of virulence genes in the isolates marks their role in the establishment of the disease and thus modulates the clinical presentation in the host. Increasing antibiotic resistance against quinolone reflects the misuse/ overuse of the antibiotics in the area.

\section{Authors' Contributions}

NR collected the samples and analyzed the samples. M designed the study. DK performed analysis of the data and AKU provided help as and when required and edited the manuscript. All authors have read and approved the final manuscript.

\section{Acknowledgments}

The authors acknowledge the funds provided by the Indian Council of Agricultural Research, New Delhi, India to carry out the research work under a project on "Outreach Programme on Zoonotic Diseases (F.No. 14(1)2009-ASR-IV)" and Govind Ballabh Pant University of Agriculture and Technology, Uttarakhand, for providing further financial assistance under the Institutional Grant.

\section{Competing Interests}

The authors declare that they have no competing interests.

\section{References}

1. Zhao, S., Young, S.R., Tong, E., Abbott, J.W., Womack, N., Friedman, S.L. and McDermott, P.F. (2010) Antimicrobial resistance of Campylobacter isolates from retail meat in the United States: 2002-2007. Appl. Environ. Microbiol., 76(24): 7949-7956.

2. Khan, J.A., Rathore, R.S., Abulreesh, H.H., Qais, F.A. and Ahmad, I. (2018) Prevalence and antibiotic resistance profiles of Campylobacter jejuni isolated from poultry meat and related samples at retail shops in Northern India. Foodborne Pathog. Dis., 15(4): 218-225.

3. Stella, S., Soncini, G., Ziino, G., Panebianco, A., Pedonese, F., Nuvoloni, R., Di Gianntale, E., Colavita, G., Alberghini, L. and Giaccone, V. (2017) Prevalence and quantification of thermophilic Campylobacter spp. In Italian retail poultry meat: Analysis of influencing factors. Food Microbiol., 62(1): 232-238.

4. Duque, B., Daviaud, S., Guillou, S., Haddad, N. and Membre, J.M. (2017) Quantification of Campylobacter jejuni contamination on chicken carcasses in France. Food 
Res. Int., 106: 1077-1085.

5. Calva, J.J., Ruiz-Palacioz, G.M., Lopez-Vidal, A.B., Ramos, A. and Bojalil, R. (1988) Cohort study of intestinal infection with Campylobacter in Mexican children. Lancet, 1(8584): 503-506

6. Salim, S.M., Mandal, J. and Parija, S.C. (2014) Isolation of Campylobacter from human stool samples. Indian J. Med. Microbiol., 32(1): 35-38.

7. Gorkiewicz, G., Feierl, G., Schober, C., Dieber, F., Kofer, J., Zechner, R. and Zechner, E.L. (2003) Species-specific identification of Campylobacters by partial $16 \mathrm{~S} r R N A$ gene sequencing. J. Clin. Microbiol., 41(6): 2537-2546.

8. Wieczorek, K. and Osek, J. (2013) Antimicrobial resistance mechanisms among Campylobacter. Biomed. Res. Int., 2013(6726): 340605 .

9. Corry, J.E.L., Atabay, H.I., Forsythe, S.J. and Mansfield, L.P. (2003) Culture media for the isolation of Campylobacters, Helicobacter and Arcobacters. In: Corry, J.E.L., Curtis, G.D.W. and Baird, R.M., editors. Handbook of Culture Media for Food Microbiology. $2^{\text {nd }}$ ed. Elsevier, Amsterdam, The Netherlands. p271-315.

10. OIE Terrestrial Manual. (2008) C. jejuni and C. coli. OIE Terrestrial Manual, Paris. p1185-1191.

11. Linton, D., Lawson, A.J., Owen, R.J. and Stanley, J. (1997) PCR detection, identification to species level, and fingerprinting of Campylobacter jejuni and Campylobacter coli direct from diarrheic samples. J. Clin. Microbiol., 35(10): 2568-2572.

12. Nayak, R., Stewart, T.M. and Nawaz, M.S. (2005) PCR identification of Campylobacter coli and Campylobacter jejuni by partial sequencing of virulence genes. Mol. Cell. Probes., 19(3): 187-193.

13. Oyofo, B.A., Thornton, S.A., Burr, D.H., Trust, T.J., Pavlovskis, O.R. and Guerry, P. (1992) Specific detection of $C$. jejuni and $C$. coli by using the polymerase chain reaction. J. Clin. Microbiol., 30(10): 2613-2619.

14. Datta, S., Niwa, H. and Itoh, K. (2003) Prevalence of 11 pathogenic genes of $C$. jejuni by PCR in strains isolated from humans, poultry meat and broiler and bovine faeces. J. Med. Microbiol., 52(4): 345-348.

15. Biswas, D., Hannon, S.J., Townsend, H.G., Potter, A. and Allan, B.J. (2011) Genes coding for virulence determinants of $C$. jejuni in human clinical and cattle isolates from Alberta, Canada, and their potential role in colonization of poultry. Int. Microbiol., 14(1): 25-32.

16. Taremi, M., Mehdi, M., Dallal, S., Gachkar, L., MoezArdalan, S. and Zolfagharian, K. (2006) Prevalence and antimicrobial resistance of Campylobacter isolated from retail raw chicken and beef meat, Tehran, Iran. Int. $J$. Food Microbiol., 108(3): 401-403.

17. Rajagunalan, S. (2010) Isolation, PCR Based Identification and Fla Typing of Thermophilic Campylobacters. M.V.Sc. Thesis Submitted to G.B.P.U.A and T, Pantnagar.

18. Pandey, R. (2015) Biochemical and Molecular Characterization of Thermophilic Campylobacters Isolated from Man and Farm Animals. M.V.Sc. Thesis submitted to G.B.P.U.A and T, Pantnagar.

19. Pant, K. (2011) Isolation, Identification and Molecular Characterization of Campylobacter jejuni and C. coli. M.V.Sc. Thesis Submitted to G.B.P.U.A and T, Pantnagar.

20. Kumar, P. (2013) Isolation and Molecular Characterization of $C$. jejuni and C. coli from Human and Poultry Caeca as Well as Meat. M.V.Sc. Thesis Submitted to G.B.P.U.A and T, Pantnagar.

21. Monika, J. (2014) Isolation, Epidemiology, Molecular Characterization and Antibiogram of Campylobacter from meat. M.V.Sc. Thesis Submitted to G.B.P.U.A and T, Pantnagar.

22. Rajendran, P., Babji, S., George, A.T., Rajan, D.P., Kang, G. and Ajjampur, S.S. (2012) Detection and species identification of Campylobacter in stool samples of children and animals from Vellore, South India. Indian J. Med. Microbiol.,
30(1): $85-88$.

23. Deckert, A., Valdivieso-Garcia, A., Reid-Smith, R. Tamblyn, S., Seliske, P., Irwin, R., Dewey, C., Boerlin, P. and McEwen, S.A. (2010) Prevalence and antimicrobial resistance in Campylobacter spp. Isolated from retail chicken in two health units in Ontario. J. Food Prot., 73(7): 1317-1312.

24. Desmonts, M.H., Dufour-Gesbert, F., Avrain, L. and Kempf, I. (2004) Antimicrobial resistance in Campylobacter strains isolated from French broilers before and after antimicrobial growth promoter bans. J. Antimicrob. Chemother., 54(6): 1025-1030.

25. Humphrey, T., O'Brien, S. and Madsen, M. (2007) Campylobacters as zoonotic pathogens: A food production perspective. Int. J. Food Microbiol., 117(3): 237-257.

26. Salihu, M.D., Junaidu, A.U., Oboegbulem, S.I., Egwu, G.O., Tambuwal, F.M. and Yakubu, Y. (2009) Prevalence of Campylobacter species in apparently healthy goats in Sokoto State (Northwestern) Nigeria. Afr. J. Microbiol. Res., 3(9): 572-574.

27. Zweifel, C., Zychowska, M.A. and Stephan, R. (2004) Prevalence and characteristics of Shiga toxin-producing Escherichia coli, Salmonella spp., and Campylobacter spp. Isolated from slaughtered sheep in Switzerland. Int. J. Food Microbiol., 92(1): 45-53.

28. Cortes, C., de la Fuente, R., Contreras, A., Sanchez, A., Corrales, J.C., Martinez, S. and Orden, J.A. (2006) A survey of Salmonella spp., and Campylobacter spp. In dairy goat faeces and bulk tank milk in the Murcia region of Spain. Ir. Vet. J., 59(7): 391-393.

29. Lazou, T., Dovas, C., Houf, K., Soultos, N. and Iossifidou, E. (2014) Diversity of Campylobacter in retail meat and liver of lambs and goat kids. Foodborne Pathog. Dis., 11(4): 320-328.

30. Mpalang, R.K., Boreux, R., Melin, P., Bitiang, K.A.N., Daube, G. and Mol, P.D. (2014) Prevalence of Campylobacter among goats and retail goat meat in Congo. J. Infect. Dev. Ctries., 8(2): 168-175.

31. Karikari, A.B., Obiri-Danso, K., Frimpong, E.H. and Krogfelt, K.A. (2017) Antibiotic resistance of Campylobacter recovered from faeces and carcasses of healthy livestock. Bio. Med. Res. Int., 2017: 4091856.

32. Jensen, A.N., Dalsgaard, A., Baggesen, D.L. and Nielsen, E.M. (2006) The occurrence and characterization of Campylobacter jejuni and C. coli in organic pigs and their outdoor environment. Vet. Microbiol., 116(1-3): 96-105.

33. Nkogwe, C., Raletobana, J., Stewart-Johnson, A., Suepaul, S. and Adesiyun, A. (2011) Frequency of detection of Escherichia coli, Salmonella spp., and Campylobacter spp. In the faeces of wild rats (Rattus spp.) in Trinidad and Tobago. Vet. Med. Int., 2011: 1-7.

34. Konkel, M.E., Gray, S.A., Kim, B.J., Garvis, S.G. and Yoon, J. (1999) Identification of the enteropathogens Campylobacter jejuni and Campylobacter coli based on the cadF virulence gene and its product. J. Clin. Microbiol., 37(3): 510-517.

35. Wieczorek, K., Denis, E., Lynch, O. and Osek, J. (2013) Molecular characterization and antibiotic resistance profiling of Campylobacter isolated from cattle in polish slaughterhouses. Food Microbiol., 34(1): 130-136.

36. Rozynek, E., Dzierzanowska-Fangrat, K., Jozwiak, P., Popowski, J., Korsak, D. and Dzierzanowska, D. (2005) Prevalence of potential virulence markers in polish Campylobacter jejuni and Campylobacter coli isolates obtained from hospitalized children and from chicken carcasses. J. Med. Microbiol., 54(7): 615-619.

37. Wieczorek, K. and Osek, J. (2011) Molecular characterization of Campylobacter spp. Isolated from poultry faeces and carcasses in Poland. Acta Vet. Brno, 80(1): 19-27.

38. Bang, D.D., Nielsen, E.M., Scheutz, F., Pedersen, K., Handberg, K. and Madsen, M. (2003) PCR detection of seven virulence and toxin genes of Campylobacter jejuni 
and Campylobacter coli isolates from Danish pigs and cattle and cytolethal distending toxin production of the isolates. J. Appl. Microbiol., 94(6): 1003-1014.

39. Talukder, K.A., Aslam, M., Islam, Z., Azmi, I.J., Dutta, D.K., Hossain, S., Nur-E-Kamal, A., Nair, G.B., Cravioto, A., Sack, D.A. and Endtz, H.P. (2008) Prevalence of virulence genes and cytolethal distending toxin production in C. jejuni isolates from diarrheal patients in Bangladesh. J. Clin. Microbiol., 46(4): 1485-1488.

40. Koolman, L., Whyte, P., Burgess, C. and Bolton, D. (2015) Distribution of virulence-associated genes in a selection of Campylobacter isolates. Foodborne Pathog. Dis., 12(5): 424-432.

41. Jribi, H., Sellami, H., Hassena, A.B. and Gdoura, R. (2017) Prevalence of putative virulence genes in Campylobacter and Arcobacter species isolated from poultry and poultry by-products in Tunisia. J. Food Prot., 80(10): 1705-1710.

42. Melo, R.T., Nalevaiko, P.C., Mendonça, E.P., Borges, L.W., Fonseca, B.B., Marcelo, E., Beletti, M.E. and Rossi, D.A. (2013) Campylobacter jejuni strains isolated from chicken meat harbour several virulence factors and represent a potential risk to humans. Food Control, 33(1): 227-231.

43. Ruiz, J., Marco, F., Oliveira, I., Vila, J. and Gascon, J. (2007) Trends in antimicrobial resistance in Campylobacter spp.
Causing traveler's diarrhea. Acta Pathol. Microbiol. Immunol. Scand., 115(3): 218-224.

44. Jain, D., Sinha, S., Prasad, K.N. and Pandey, C.M. (2005) Campylobacter species and drug resistance in a North Indian rural community. Trans. R. Soc. Trop. Med. Hyg., 99(3): 207-214.

45. Qin, S.S., Wu, C.M. and Wang, Y. (2011) Antimicrobial resistance in $C$. coli isolated from pigs in two provinces of China. Int. J. Food Microbiol., 146(1): 94-98.

46. Sonnevend, A., Rotimi, V.O., Kolodziejek, J., Usmani, A., Nowotny, N. and Pal, T. (2006) High level of ciprofloxacin resistance and its molecular background among $C$. jejuni strains isolated in the United Arab Emirates. J. Med. Microbiol., 55(11): 1533-1538.

47. Bester, L.A. and Essack, S.Y. (2008) Prevalence of antibiotic resistance in Campylobacter isolates from commercial poultry suppliers in KwaZulu-Natal, South Africa. J. Antimicrob. Chemother, 62(6): 1298-1300.

48. Szczepanska, B., Andrzejewska, M., Spica, D. and Klawe, J.J. (2017) Prevalence and antimicrobial resistance of Campylobacter jejuni and Campylobacter coli isolated from children and environmental sources in urban and suburban areas. BMC Microbiol., 17(1): 80. 